\title{
EFFECT OF WEATHERING ON WOOD TREATED WITH TALL OIL COMBINED WITH SOME ADDITIVES
}

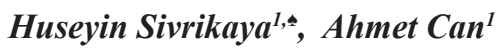

\begin{abstract}
Growing interest on bio-based material has led to focus on environmentally benign wood treatment systems because of the environmental concerns. Tall oil is a by-product from pulp and paper industry, contains resin and fatty acids, and is biodegradable. Tall oil treated wood can provide some reduction in water uptake and increase in decay resistance. In this research crude tall oil was dissolved in ethanol at 5,10 and $15 \%$ concentrations in the treatment of Scots pine according to full cell process. Dyestuff, iron oxide and sodium ascorbate were used an additive as $0,5 \%$. Weathering performance of tall oil and tall oil combined with additives were investigated in accelerated weathering chamber by application of ultraviolet irradiation and water spray. It is taken for granted that increasing concentration results in higher weight percent gain in treated samples. The best results were obtained with $10 \%$ tall oil and iron oxide which indicated minimum total color changes. Colour measurements and visual examination revealed that iron oxide was the most effective additive in reducing weathering effect and lowering the total colour change.
\end{abstract}

Keywords: Colour, dyestuff, iron oxide, Scots pine, sodium ascorbate.

\section{INTRODUCTION}

Wood can be treated with preservatives to improve decay and water resistance, photodegradation and fire retardance when expose to adverse conditions. Since wood in given situations is susceptible to fungal deterioration wood preservatives are used. Most wood protection systems rely on a toxic mode of action against biological deterioration, but these preservatives are hampered with some potential environmental concerns (Rowell 2006).

There is growing interest on the non-biocidal treatments like wood modification, biodegradable substances and bio based materials in recent years since they are environmentally friendly process. Tall oil is known an environmentally friendly, biodegradable, can reduce water uptake (Van Eckeveld et al. 2001) and the growth of fungi in wood (Paajanen and Ritschkoff 2002). It is obtained as a by-product from softwoods according to kraft process in the production of pulp. To production of purified crude tall oil (CTO) in the sulphate pulping process, tall oil soap is separated from the pulping liquor. Tall oil fatty acids, tall oil rosin, distilled tall oil, tall oil heads, and tall oil pitch are the refined products by fractional distillation of CTO (Ramanen 2014).

Koski (2008) described the problems to be solved with regard to wood protection with crude tall oil as follow; emulsion technique to reduce high amount of tall oil used in wood protection, using of iron catalysts to improve oxidation rate of crude tall oil and inhibition of the oil exudation from wood, improving the drying properties of the emulsion oil phase and retaining the high water-repellent efficiency. In a field trial, the performance of different tall oils were compared in three different above ground field tests for nine years and two in ground exposure trials for ten years. Tall oil having retention

${ }^{1}$ Forest Industry Engineering, Faculty of Forest, Bartin University, Bartin, Turkey.

•Corresponding author: hsivrikaya@bartin.edu.tr

Received: 23.02.2016 Accepted: 25.08.2016 
at $200-250 \mathrm{~kg} / \mathrm{m}^{3}$ delayed the decay when compared to control samples, but it did not perform as well as copper reference preservatives. It was proposed that tall oil should be used in combination with biocides in wood protection (Alfredsen and Flaete 2015).

Hyvönen et al. (2007a) studied to enhance the drying properties of crude tall oil, and they emphasized that oxidation rate of tall oil could be improved by means of iron catalyst in order to prevent the oil exudation from wood. Furthermore, iron catalyst improved the properties of wood treated with tall oil emulsion in terms of drying and reduced water uptake (Hyvönen et al. 2007b).

Can and Sivrikaya (2016) investigated the water repellent property of tall oil dissolved in different solvents such as ethanol, methanol, acetone and oil-in-water, resulting in almost equal efficiency for each formulation in Scots pine and fir sapwood.

Wood is susceptible to environmental degradation, when exposed to outdoor is subjected to Photodegradation by UV, leaching, hydrolysis and swelling by Water, discoloration and degradation by staining and decay micro-organisms. The decrease in hemicellulose, cellulose and lignin content of wood has been observed when wood exposed to outdoor conditions. (Cademartori et al. 2015, Saei et al. 2015). Surface of the exposed wood is affected by Physical and chemical changes caused by weathering. However, wood surface can be protected by paints, stains, or varnishes against weathering effect (Feist 1983).

The reason of failure of the organic coatings is photodegradation due to the UV exposure. Inorganic UV-absorbing materials can be applied for absorption or scattering light (Salla et al. 2012).

Several inorganic UV absorbers has been used such as titanium dioxide, cerium dioxide or zinc oxide are used for improving wood surfaces against to UV radiation, water, mildew, fungus growth,stains and grease (Cristea et al. 2010). Inorganic UV absorbers have received a great deal of attention in transparent wood coatings since they are UV blockers for the last decade (Aloui et al. 2007). It is referred that iron oxide pigments have excellent durability, high inherent opacity, good UVscreening properties, low toxicity and low cost (Kiguchi et al. 2007).

$\mathrm{TiO}_{2}$ nanoparticles are one of the metallic oxides, included in the coatings as UV absorber due to the their broad UV spectrum and photostabilization property (Fufa et al. 2013).

Zinc oxide is known a UV stabilizer and preservative component in wood coatings (Cristea et al. 2012, Can and Sivrikaya 2014). Impregnation of wood with $\mathrm{ZnO}$ nano particles improved the weathering resistance of wood (Clausen et al. 2010). Auclair et al. (2011) reported that the mixture of inorganic and organic UV absorbers displayed synergistic effect with regard to glossiness of the coatings.

The researches were conducted on tall oil treated wood were mostly regarding the decay resistance and water uptake in wood. Previous studies proved that tall oil increase decay resistance and reduce water uptake in wood. The objective of this research was to investigate the accelerated weathering resistance of tall oil as such and tall oil in combination with additives dyestuff, iron oxide and sodium ascorbate in the protection of wood.

\section{MATERIALS AND METHODS}

\section{Treatment of wood samples}

Wood samples were prepared from Scots pine sapwood (Pinus sylvestris), cut in to small sizes of $150 \times 75 \times 15 \mathrm{~mm}$ (LxRxT) as test material. Four replicate samples were used in whole experiments. Crude tall oil was obtained from OYKA pulp and paper factory running according to kraft process, located in Çaycuma district in Turkey. Tall oil was dissolved in ethanol at 5, 10 and $15 \%$ concentrations. Tall oil solution mixed with some additives $(0,5 \%)$ such as red dyestuff (Red 119$)$, iron oxide pigment 
(red) having UV stability and Sodium ascorbate as an antioxidant. 0,5\% additives is related to tall oil weight. Sodium ascorbate was dissolved in water and other additives in ethanol. Fe-oxide remained suspended in tall oil. The samples were treated in a chamber under vacuum $650 \mathrm{mmHg}$ for 30 minutes followed by air pressure ( 6 bar) for 30 minutes according to full cell process.

Weight percent gain (WPG) was calculated according to formula 1;

$$
W P G(\%)=\left[\left(W_{t}-W_{o}\right) / W_{o}\right] \times 100
$$
wood.

Where $\mathrm{W}_{\mathrm{t}}$ is the oven dry weight of treated samples and $\mathrm{W}_{\mathrm{o}}$ is the oven dry weight of untreated

\section{Accelerated weathering}

Weathering performance was carried out in the accelerated weathering chamber (QUV Accelerated Weathering Tester, Q-Lab Corporation Westlake US), in which wood samples exposed to UV radiation for 8 hours with the intensity of $0,75 \mathrm{~W} / \mathrm{m}^{2}, 15$ minute for water spray, conditioning for 3,45 hours at the temperature of $50{ }^{\circ} \mathrm{C}$ for each cycle to 500 hours total exposure. The changes in colour (L,a,b) and glossiness were measured for $125,250,375$ and 500 hours successively during the weathering process.

\section{Measurement of colour and glossiness}

The samples were conditioned to $12 \%$ moisture content before color and gloss measurement. Colour measurement was performed with a Konica Minolta spectrophotometer (Osaka, Japan) by measuring $\mathrm{L}, \mathrm{a}, \mathrm{b}$ values on the samples. Four replicates samples were used for the colour measurements to evaluate the $\Delta \mathrm{L}^{*}, \Delta \mathrm{a}^{*}$ and $\Delta \mathrm{b}^{*}$ as well as total colour change $\left(\Delta \mathrm{E}^{*}\right)$. The changes in colour coordinates $\left(\Delta \mathrm{L}^{*}\right.$, $\left.\Delta \mathrm{a}^{*}, \Delta \mathrm{b}^{*}\right)$ were determined by difference between the final and initial value. Three measurements were performed on each surface of four replicate samples.

Total colour change $\left(\Delta \mathrm{E}^{*}\right)$ was calculated according to equation below;

$$
\left(\Delta \mathrm{E}^{*}\right)=\left[\left(\Delta \mathrm{a}^{*}\right)^{2}+\left(\Delta \mathrm{b}^{*}\right)^{2}+\left(\Delta \mathrm{L}^{*}\right)^{2}\right]^{1 / 2}
$$

\section{Measurement of contact angle}

Contact angles of droplets on wooden surfaces were determined by Krüss G 10 contact angle measuring system, with software Krüss DSA 1. To the measurement of contact angle, a droplet of distilled $(11 \mu \mathrm{l})$ water was applied for each sample and a video was recorded for $10 \mathrm{~s}(25 \mathrm{frames} / \mathrm{sec})$. An application of the droplet was occurred during $10 \mathrm{~s}$. To evaluate the videos, a circle was fitted to each droplet and automatically for each frame, and the angle was measured between the surface and the tangent to the circle at the point of intersection.

\section{RESULTS AND DISCUSSION}

\section{Weight percent gain (WPG)}

The mean value of the weight percent gain of the treated samples is given in Table 1 .

It is clearly shown in Table 1 that the higher concentration in tall oil led to more weight uptake. Table 1 indicates that tall oil (15\%) resulted in the highest WPG in all experiments, whereas tall oil $5 \%+$ red dye had the lowest WPG. The weight uptake was higher in tall oil treatments alone $(5,10$ and $15 \%$ ) when compared to combination of this compound with additives. This might be attributed to the molecular size of additives. Previous report on the SEM images showed that the tall oil treated specimens well penetrated during the impregnation step (Lahtela and Karki 2014). 
Table 1. Weight percent gain (WPG) of the test samples.

\begin{tabular}{|l|c|}
\hline Treatment* & WPG (\%) \\
\hline TO $5 \%$ & $10,29 \pm 0,34$ \\
TO $10 \%$ & $17,24 \pm 0,70$ \\
TO $15 \%$ & $26,05 \pm 0,45$ \\
\hline TO $5 \%+$ RD & $4,80 \pm 0,49$ \\
TO $10 \%+$ RD & $10,21 \pm 0,33$ \\
TO $15 \%+$ RD & $14,61 \pm 2,09$ \\
\hline TO 5 $\%+$ IO & $6,45 \pm 0,20$ \\
TO $10 \%+$ IO & $7,39 \pm 0,78$ \\
TO $15 \%+$ IO & $9,23 \pm 0,40$ \\
\hline TO $5 \%+$ SA & $6,92 \pm 0,90$ \\
TO $10 \%+$ SA & $13,52 \pm 0,78$ \\
TO $15 \%+$ SA & $15,01 \pm 2,15$ \\
\hline
\end{tabular}

*TO: Tall oil, RD: Red dye stuff, IO: Iron oxide, SA: Sodium ascorbate

\section{Colour change}

$\Delta \mathrm{L}^{*}$ was calculated from the difference in $\mathrm{L}$ values before and after accelerated weathering for each cycle (125 hours) throughout the experiments. The results are given in Figure 1.

Untreated samples (Control) tended to be darkness since it was located below the axis in Figure 1. While the negative peak of control samples $(-14,52)$ was great during the 125 hours irradiation, it was then stable for subsequent cycles. This explains that lightness was effectively decreased in 125 hours by UV light. The variation in lightness was attributed to wood moisture content and reflectance of light on the wood surface which was exposed to natural weathering (Pfeffer et al. 2012). The dark brown colour was indicated by Feist and Hon (1984) for 1000 hours UV light exposure, whereas from pale yellow to light brown after $500 \mathrm{~h}$ exposure.

The lightness increased in the tall oil treated samples with red dye at the concentrations of 5,10 and $15 \%$, reached up to value of 17 , which indicated that lightness was not negatively affected by weathering due to the red hue.

In the absence of additives, lightness slightly increased when the concentration of tall oil increased as shown in Figure 1. In the case of the addition of iron oxide pigment, the samples showed darkness for all cycles, but the level of darkness was less in the combination of $15 \%$ of tall oil than 5 and $10 \%$.

The change in $\Delta \mathrm{L}^{*}$ for 5 and $15 \%$ of tall oil with sodium ascorbate (SA) was minor, but it was higher with $10 \%$ of tall oil after 500 hours exposure.

At the initial cycle of the weathering process (125 hours), $\Delta \mathrm{a}^{*}$ values of the control samples tended to be increasing positively that implies the red hue, which was retained about same level as long as weathering process. However, the samples treated with $5 \%$ tall oil and red dye decreased continuously in negative axis, made peak at $-17,56$ which revealed the green hue. The effect of sodium ascorbate as an additive on $\Delta \mathrm{a}^{*}$ was minor, ranged from $-0,5$ to 1 at the last cycle. 

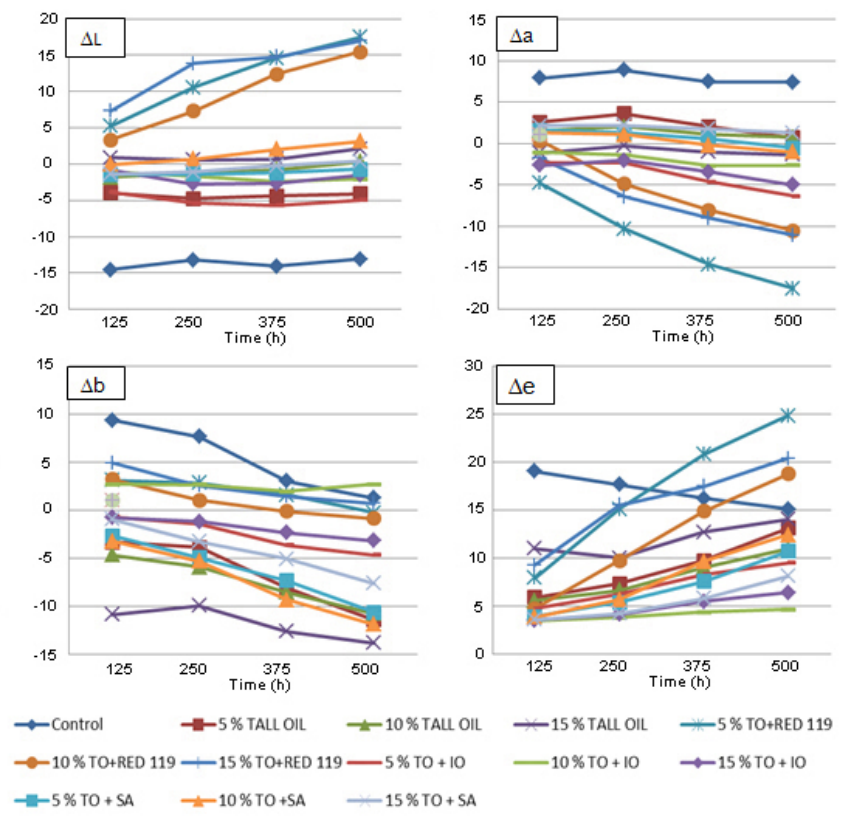

Figure 1. Colour changes of wood samples exposed to accelerated weathering.

In Figure $1, \Delta b^{*}$ values demonstrate the yellow hue which is on the $\mathrm{x}$-axis and blue hue being under the $\mathrm{x}$-axis. It was shown that first cycle of weathering increased the yellowness in the control samples, but following cycles receded the yellow hue. Yellowing or browning is the initial colour change of wood due to the sunlight exposition that finally results in graying in colour. These changes in colour can be related to the decomposition of lignin in the wood cell wall in the surface (Feist 1990). The blue hue prevailed in the samples treated with tall oil alone for all cycles, giving the highest value with $15 \%$ concentrations $(-13,79)$ for 500 hours. The adding of sodium ascorbate yielded results regarding blue hue, similar to tall oil treated samples except for $15 \%$ tall oil at final cycle.

Figure 1 presents that the remarkable total change in $\Delta \mathrm{E}^{*}$ was shown in untreated Scots pine (control) samples (19) after 125 hours weathering, whereas the highest change in colour were obtained by the samples treated with $5 \%$ tall oil with red dye for 375 hours $(20,76)$ and 500 hours $(24,81)$ respectively. Sharratt et al. (2009) performed a detailed experiment on the early colour change in Scots pine, reported that the majority of colour changes occurred within the first $24 \mathrm{~h}$ by accelerated weathering. In case of natural weathering of Scots pine, Pfeffer et al. (2012) indicated that rapid change in colour occurred during 6 months, because lignin strongly absorbs UV light (Baysal et al. 2014).

Total colour change was higher in the samples treated with $15 \%$ tall oil alone than that of 5 and 10 $\%$ for all cycles during the weathering process, however, this marked difference which was shown in the first cycle, then was lowered by further cycles during the process. This finding is supported by Figure 2, which demonstrates the heavy effect of UV radiation on the tall oil treated samples irrespective of the concentration. It was concluded from the colour measurement and visual findings (Figure 2) that tall oil treatment alone were not sufficient to show resistant against weathering.

Lahtela and Karki (2014) observed the weathering behaviour of Scots pine treated with tall oil as well as other modifying agents in the test chamber for 100,200 and 300 hours respectively. The colour change $\left(\Delta \mathrm{E}^{*}\right)$ for tall oil treated samples was 12,$1 ; 10,1$ and 10,7 for the mentioned exposure times. These results were consistent with the colour change of $15 \%$ of tall oil in our experiment in which the values were 10,97; 10 and 12,67 for the exposure of 125, 250 and 375 hours respectively. 
The effect of weathering conditions on red dyestuff was greater than other additives iron oxide and sodium ascorbate, even control samples due to the high colour change occurred in the samples of tall oil combinations with dyestuff. Although tall oil treated samples was absolutely coloured by red dye, it was not sufficient to stabilize the colour against weathering.

The great color change of the samples treated Red 119 were due to the leaching of the colorant as it was water soluble. This means that colorant was washed out, thus could not protect the wood from photodegradation. The highest change in colour was observed on the samples treated with tall oil (5\%) and red dye, while the lowest change was achieved by tall oil treatment $(10 \%)$ with iron oxide. The significant finding in relation to colour change was that the better results were obtained by iron oxide additive and $10 \%$ of tall oil for giving the lowest colour change. This finding reveals the compatibility of tall oil and iron oxide pigment against weathering. Fe-oxide, on the other hand, stains the wood dark and is probably insoluble in water. This might be the reason why the degree of color change is low, but this does not necessarily mean, that it photo-stabilizes the wood surface.

Four kinds of iron oxide pigments were compared by adding them into wood-fiber/high-densitypolyethylene composites (WF/HDPE) at three different concentrations. After $200 \mathrm{~h}$ accelerated weathering test, iron oxide red and black performed better than the other two pigments, the ratio of the pigments was found promising at 2,28 \% (Zhang et al. 2010).

When iron oxide was used as an additive in wood plastic composite (WPC), showed better performance indicating less colour change against hygrothermal aging for 70 days in comparison to samples without pigment (Xu et al. 2015). Aloui et al. (2007) compared to performance of organic and inorganic UV absorbers in the photostabilisation of wood to seek possible synergies and the influences of different wood species. The colour change was higher with iron oxide than organic UV absorbers.

Schauwecker et al. (2014) suggested that much higher levels of iron oxide are needed to prevent discoloration and limit lignin degradation that was resulted from their research which investigated the influence of iron oxides (1000 ppm) with different crystal shapes and particle sizes on the weathering characteristics of wood surfaces. In addition, red iron oxide treatments provided more protection against discoloration than similarly sized yellow iron oxides in their research. Besides, low concentrations of iron oxides even were promising to reduce lignin loss and discoloration according to previous results (Schauwecker 2010, Schauwecker et al. 2013).

Tall oil treated samples did not resulted in satisfactory results in relation to colour change when oil accompanied with sodium ascorbate which should be studied at higher concentrations, moreover no research was conducted on weathering of wood treated with sodium ascorbate. The mode of action of ascorbate might be that it is a radical scavenger and prevents oxidative decay of tall oil and wood. However, ascorbate is water soluble and is therefore washed out during the first spray cycle. It can thus execute its mode of action only during the first cycle of UV exposure. It was referred that metal ions provide light stability by creating free radicals when wood exposed to light (Yeniocak et al. 2015).

As a general result, the colour change increased linearly from beginning to following cycles in the samples showing poor weathering resistance. It means that these protective systems studied in the experiment could not prevent the lignin photodegradation on the samples. 


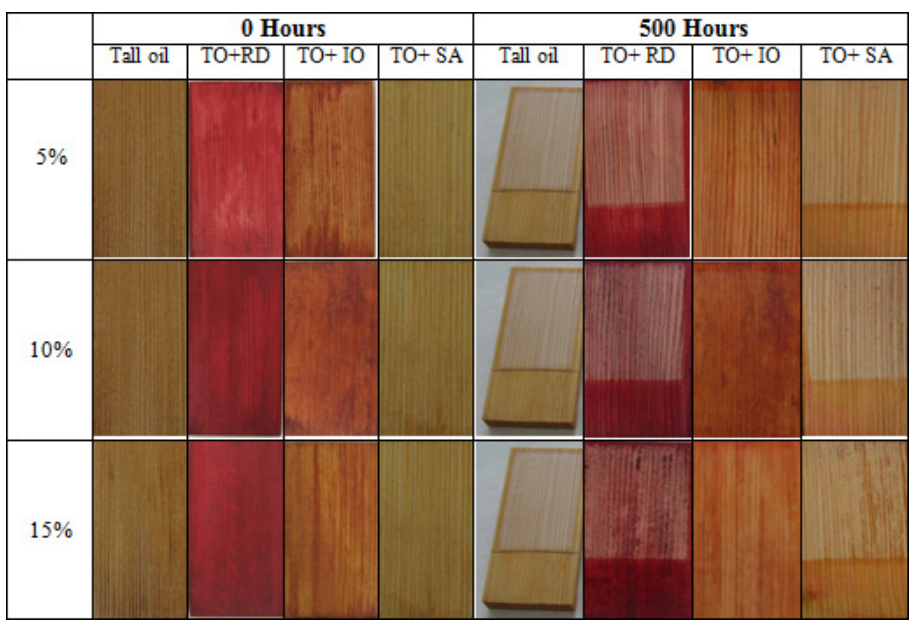

Figure 2. Tall oil treated samples before and after 500 hours weathering.

\section{Contact angle}

Contact angle was measured for the samples before weathering and after exposed to weathering, and the results are given in Figure 3.

As can be seen from Figure 3, there was clearly difference in contact angle values before $\left(110^{\circ}\right)$ and after weathering $\left(74^{\circ}\right)$ for untreated Scots pine. This can be attributed to the hydrophilic surface of the control samples because of the cellulosic rich fibers on the surface as a result of lignin degradation and application of water spray in weathering chamber, leading to increased wettability. According to Kalnins and Knaebe (1992) contact angles progressively decreased in western red cedar since the wettability increased during the 12 weeks of outdoor weathering, whereas it increased in the earlier times of weathering in southern pine but decreased afterwards.

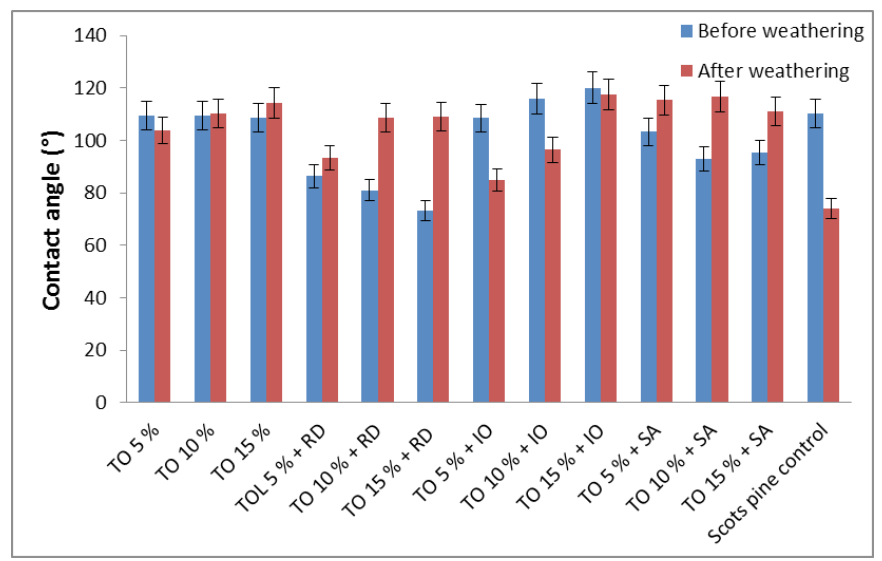

Figure 3. Contact angle values of the samples before and after weathering.

Besides, wetting cycle and constant temperature $\left(50^{\circ} \mathrm{C}\right)$ might promote the crack formation which decreases the contact angle on the wood surface. Because, the surface of tall oil treated Scots pine with SEM was also investigated by Lahtela and Karki (2014) and they demonstrated that the cracking on the surface was due to the weathering effect. The fiber swelling due to the wetting can be considered another factor for a reason of reduced contact angle for control samples of Scots pine. 
After $500 \mathrm{~h}$ weathering, little increase was seen in contact angle for tall oil treatment at 10 and $15 \%$ concentration, whereas little decrease found at $5 \%$ concentration. Contact angle was lower in untreated Scots pine than that of the samples treated with tall oil after weathering exposure. This difference might be attributed to the tall oil contents such as resin and fatty acids.

It was interesting that the addition of red dye in to tall oil increased the contact angle even though weathering effect. Because, red dye has no hydrophobic character, and it was not found resistant to UV radiation, therefore leached out during the weathering process and probably led to increasing in contact angle.

The additive of iron oxide resulted in lower contact angle after weathering in comparison to pre weathering although it was considerably resistant to UV light as shown in Figure 2 as well. Combination with sodium ascorbate as anti-oxidant had positive effect on the contact angle after 500 hours exposure.

\section{CONCLUSIONS}

Present study indicated that tall oil treatment was not found resistant to weathering when used alone in wood. The surface of the tall oil treated samples was greatly bleached by UV radiation irrespective of the tall oil concentration. Tall oil treated samples must be combined with additives against weathering effect when it is used outdoor conditions. Iron oxide was found to be effective in reducing the weathering effect, resulted in the lowest colour change, even though exhibited lower contact angle in weathered samples when compared to the samples before weathering. $10 \%$ concentration of tall oil was found optimum in order to have low colour change. The results were promising for further studies that should be done with higher concentration of additives in combination with $10 \%$ of tall oil in order to obtain biobased material for outdoor.

\section{ACKNOWLEDGMENTS}

The authors would like to thank Lena Wallenhorst from HAWK-Göttingen for helping in the measurement of contact angle.

\section{REFERENCES}

Alfredsen, G.; Flaete, P. 2015. Tall oil - performance after a decade of field exposure. IRG/WP $15-30672,46^{\text {th }}$ IRG Annual Meeting, Viña del Mar, Chile.

Aloui, F.; Abajji, A; Irmouli, Y; George, B; Charrier, B; Merlin, A. 2007. Inorganic UV absorbers for the photostabilisation of wood-clearcoating systems: Comparison with organic UV absorbers. Applied Surface Science 253:3737-3745.

Auclair, N.; Bernard, R.; Vincent, B.; Pierre, B. 2011. Improvement of Photoprotection of Wood Coatings by Using Inorganic Nanoparticles as Ultraviolet Absorbers. Forest Prod J 61(1):20-27.

Baysal, E.; Degirmentepe, S.; Simsek, H. 2014. Some surface properties of thermally modified scots pine after artificial weathering. Maderas-Cienc Tecnol 16(3):355-364. 
Can, A.; Sivrikaya, H. 2014. Effects Of Nano-Zinc Oxide Based Paint On Weathering Performance of Coated Wood. Proceedings of the $3^{\text {rd }}$ International Conference on Processing Technologies for the Forest and Bio-based Products Industries (PTF BPI 2014) Kuchl/ Salzburg, Austria,September 24-26, 2014.

Can, A.; Sivrikaya, H. 2016. Dimensional stabilization of wood treated with tall oil dissolved in different solvents. Maderas-Cienc Tecnol 18(2):317-324.

Clausen, C.A.; Green, F III.; Kartal, S.N. 2010. Weatherability and leach resistance of wood impregnated with nano-zinc oxide. Nanoscale Res Lett 5:1464-1467.

Cristea, M.V.; Riedl, B.; Blanchet. P. 2010. Enhancing the performance of exteriorwaterborne coatings for wood by inorganic nanosized UV absorbers. Progress in OrganicCoatings 69(4):432-441.

Cristea, M.V.; Riedl, B.; Blanchet, P.; Jimenez-Pique, E. 2012. Nanocharacterizationtechniques for investigation the durability of wood coatings. European Polymer Journal 48:441-453.

Gonzalez de Cademartori, P. H.; Missio, A. L.; Dufau Mattos, B.; Gatto, D. A. 2015. Natural weathering performance of three fast-growing Eucalypt woods. Maderas-Cienc Tecnol 17(4):799-808.

Feist, W.C. 1983. Weathering and protection of wood. In: Proceedings $79^{\text {th }}$ Annual meeting of the American Wood Preserver's Assoc. 79:195-205.

Feist, W.C; Hon D.N.S. 1984. Chemistry of weathering and protection. In: Rowell RM (ed) The chemistry of solid wood. Am Chem Soc, Washington, pp 401-451.

Feist, W.C. 1990. Outdoor wood weathering and protection. In: Barbour RM, Rowell JR (eds) Archaeological wood: properties, chemistry and preservation. Am Chem Soc, Washington, pp 263-298.

Fufa, S.M.; Jelle, B.P.; Hovde P.J. 2013. Effects of $\mathrm{TiO}_{2}$ and clay nanoparticles loading on weathering performance of coated wood. Progress in Organic Coatings 76(10):1425-1429.

Hyvönen, A; Nelo, M; Piltonen, P; Hormi, O; Niinimaki, J. 2007a. Using iron catalyst to enhance the drying properties of crude tall oil-based wood preservative. Holz Roh Werkst 65: 105-111.

Hyvönen, A.; Nelo, M.; Piltonen, P.; Hormi, O.; Niinimaki, J. 2007b. Using the emulsion technique and an iron catalyst to enhance the wood protection properties of tall oil Holz Roh Werkst 65:247-249.

Kiguchi, M.; Kataoka, Y.; Matsunaga, H.; Yamamoto, K.; Evans, P.D. 2007. Surface deterioration of wood-flour polypropylene composites by weathering trials. Journal of Wood Science $53: 234-238$.

Kalnins, M.A.; Knaebe, M.T. 1992. Wettability of weathered wood. Journal of Adhesion Science and Technology 6(12):1325-1330.

Koski, A. 2008. Applicability of crude tall oil for wood protection. Acta Universitatis Ouluensis C Technica 293, Oulu.

Lahtela, V.; Karki, T. 2014. Improving the UV and water-resistance properties of Scots pine (Pinus sylvestris) with impregnation modifiers. Eur J Wood Prod 72:445-452.

Paajanen, L.; Ritschkoff, A.C. 2002. Effect of crude tall oil, linseed oil and rapeseed oil on the growth of the decay fungi. IRG/WP 02-30299. 
Pfeffer, A.; Mai, C.; Militz, H. 2012. Weathering characteristics of wood treated with water glass, siloxane or DMDHEU. Eur J Wood Prod 70:165-176.

Ramanen, P. 2014. Tall oil fatty acid-based alkyd acrylic copolymers: synthesis, characterization, and utilization in surface coating applications. PhD Thesis, Helsinki.

Rowell. R.M. 2006. Chemical modification of wood: A short review. Wood Material Science and Engineering 1:29-33.

Saei, A. M.; Mohebby, B.; Abdeh, M. R. 2015. Effects of oleothermal treatment and polydimethylsiloxane (PDMS) coating on natural weathering of beech and fir woods. Maderas-Cienc Tecnol 17(4):905-918.

Salla, J.; Pandey, K.K.; Srinivas, K. 2012. Improvement of UV resistance of wood surfacesby using ZnO nanoparticles. Polym Degrad Stab 97(4):592-596.

Schauwecker, C. 2010. FTIR analysis of wood surfaces treated with prospective surface protestants and exposed outdoors for various exposure periods". Evaluation of various chemical treatments to prevent the abiotic deterioration of southern pine surfaces through outdoor screening trials Ph.D. dissertation, Oregon State University. Corvallis, Oregon.

Schauwecker, C.F.; McDonald, A.G.; Morrell, J.J. 2013. Performance of wood treated with prospective organic surface protectants upon outdoor exposure: FTIR spectroscopic analysis of weathered surfaces. Holzforschung 67(2):227-235.

Schauwecker, C.F.; McDonald, A.G; Morrell, J.J. 2014. Use of iron oxides to influence the weathering characteristics of wood surfaces: a systematic survey of particle size, crystal shape and concentration. Eur J Wood Prod 72:669-680.

Sharratt, V.; Hill, C.A.S.; Kint, D.P.R. 2009. A study of early colour change due to simulated accelerated sunlight exposure in Scots pine (Pinus sylvestris). Polymer Degradation and Stability 94(9):1589-1594.

Xu, C.; Xing, C.; Pan, H.; Matuana, L.M.; Zhou, H. 2015. Hygrothermal Aging Properties of Wood Plastic Composites Made of Recycled High Density Polypropylene as Affected by Inorganic Pigments. Polymer Engineering and Science DOI 10.1002/pen.24054.

Van Eckeveld, A.; Homan, W.J.; Militz, H. 2001. Increasing the water repellency of Scots pine sapwood by impregnation with undiluted linseed oil, wood oil, coco oil and tall oil. Holzforsch Holzverw 6:113-115.

Yeniocak, M.; Goktas, O.; Colak, M.; Ozen, E.; Ugurlu, M. 2015. Natural coloration of wood material by red beetroot Beta vulgaris) and determination color stability under UV exposure. MaderasCienc Tecnol 17(4):711-722.

Zheng-ming, Z.; Hua, D.; Wei-hong, W.; Qing-wen, W. 2010. Property changes of wood-fiber/ HDPE composites colored by iron oxide pigments after accelerated UV weathering. Journal of Forestry Research 21(1):59-62. 